\title{
Investigation of the Influence of Trust on Participative Performance of Employees (Mediating Role of Commitment) in Social Security Organization Departments in Guilan Province
}

\author{
Tahmine Seydgar Ghanbar \\ Corresponding Author, M.A Student of Public Administration, Human Resources, \\ Islamic Azad University, Rasht Branch, Rasht, Iran \\ E-mail:khoshamooz_ha@yahoo.com \\ Mehrdad Goudarzvand Chegini \\ P.H.D of Public Administration, Department of Management, \\ Islamic Azad University, Rasht Branch, Rasht, Iran
}

Doi:10.5901/mjss.2014.v5n23p2777

\begin{abstract}
The present research aims to investigate the influence of trust on participative performance of employees by considering mediating role of commitment (case study: organization of social security). Statistical population of the research included all employees of social security organizations in Guilan Province in 2012. Cluster random sampling method was used for selecting 301 people out of 599 employees and finally, 300 questionnaires were analyzed. Questionnaire was used for data collection and its Cronbach's alpha was equal to 0.845. LISREL software was used for data analysis. Results of the hypotheses test showed that personal trust has a positive impact on team trust and increases it. Further, team trust had positive influence on commitment and improves employees' commitment. However, personal trust did not have any influence on commitment. Personal trust also had positive and direct impact on participation and improves participation in employees' performance. Results of the fifth and sixth hypotheses of the research showed that different types of commitment and team trust had direct and positive influence on participative performance and improve employees' participative performance in social security organization in Guilan Province.
\end{abstract}

Keywords: trust, commitment, participative performance, personal trust

\section{Introduction}

The life of any system and social institute depends on the presence of strong link among its elements. This link is affected by level of observation of justice and trust in that system. Evaluation of individuals' responses to what they give and what they obtain from their respective organizations has been subjectof many studies (Liu \&Luo, 2011). Organizational commitment refers to a positive attitude which is resulted from employees' sense of loyaltyto their organizations and is expressed by employees' participation in organizational decisions, attention to employees and their welfare (Mogimi, 2006, 392). In the present complex and diversified markets, failure to pay attention to performance and participation will eliminate organizations from competition (Branda\&Eccles, 2005). Today, organizations know that their employees' performances are very important in their competitive success. Employees' participative performance is a human asset and investment in improvement of employees' performance will directly result in high-quality products and services. Contrary to other production factors, performance is characterized by increasing incomes (Charlton \& Human, 2010).

\section{Theoretical Framework and Research Model}

Trust is one of the important bases of social and ethical philosophy and has its roots in old history. Many definitions have been presented for trust up to now. In spite of deep and widespread attempts to define and characterize trust (bayr, 1986; Bla, 1964; Lahman, 1974; Viliyamson, 1993; and Zaker, 1986), trust is not still an important subject in public departments and organizationsliterature. Management experts consider trust as an important factor in cooperation and conflict management (Lumis, 1959 and Sharif, 1966), leadership styles (Likert, 1967), managerial preconditions with respect to employees (Mac Garigor, 1960), satisfaction of needs (Maslaw, 1954), organizational change and development 
(Glombeski, 1986), participation (Milles and Ritchi, 1984), communications (Millinjer, orely and Rabert, 1967), stress and burnout (Glombeski, 1983) and social contracts (Ardris, 1960; Levinson, 1962; Eschen, 1980). In organizational behavior literature, Allen \& Meyer (1990) differentiated between different types of loyalty viewpoints and classified them based on emotional, normal and utilitarian (continuous) commitments. Differences among these three types of loyalty viewpoints are reflections of psychological place which links employees to each other. Organizational commitment is a kind of attitude which indicates employees' loyalty and interest in organization and their tendency to stay with the organization. In the present research, team trust and personal trust relationship is investigated so that we answer the question "whether personal trust results in team trust. Further, the influence of personal trust and team trust on formation of organizational trust is investigated. Moreover, commitment (normal, emotional and continuous) influence as a mediating variable on relationship between trust and participative performance was investigated.

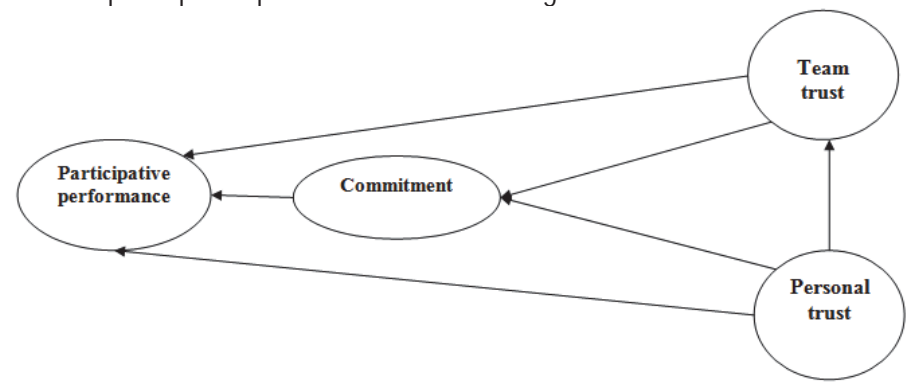

Figure 1. research model, research hypotheses

1. personal trust influences team trust.

2. Team trust influences commitment.

3. personal trust influences participative performance.

4. personal trust influences commitment.

5. team trust influences participative performance.

6. commitment has a positive impact on participative performance.

\section{Research methodology}

The present research is a descriptive one and data were collected by means of questionnaire. Statistical population of the research included 599 employees of Social Security Organization in Guilan Province. Structural equations modeling technique was used for analysis. Sample size was calculated as follows:

$.5 q \leq n \leq 15 q$

$q$ is the number of measurement variables.

Q*5 < sample size $<$ Q 15

$36 * 5<$ sample size $<36 * 15$

This means that minimum sample size is 180 and maximum sample size is 540 .

In the present research, Cocheran's formula was used for calculation of sample size and the results verified the results of the above calculations:

$\mathrm{N}=599$

$Z_{\frac{\alpha}{2}}^{2}=1.96$

$e=0.04$

$\mathrm{n}=\frac{N Z^{2} \cdot p \cdot q}{(N-1) e^{2}+Z^{2} \cdot p \cdot q}=\frac{599(1.96 * 1.96)(0.25)}{598(.0016)+(1.96 * 1.96)(0.25)}=300.73$

Therefore, sample size was 300 . Further, structural equations modeling technique was used for investigation of the elements of the model. Confirmatory factor analysis was also conducted. All calculations were conducted by means of LISREL software.

Research findings

In the present research, model parameters were calculated by means of LISREL software after graphing the model. Therefore, Gama coefficients ( ${ }^{\gamma}$ ) and t test was used for investigation of the hypotheses. 


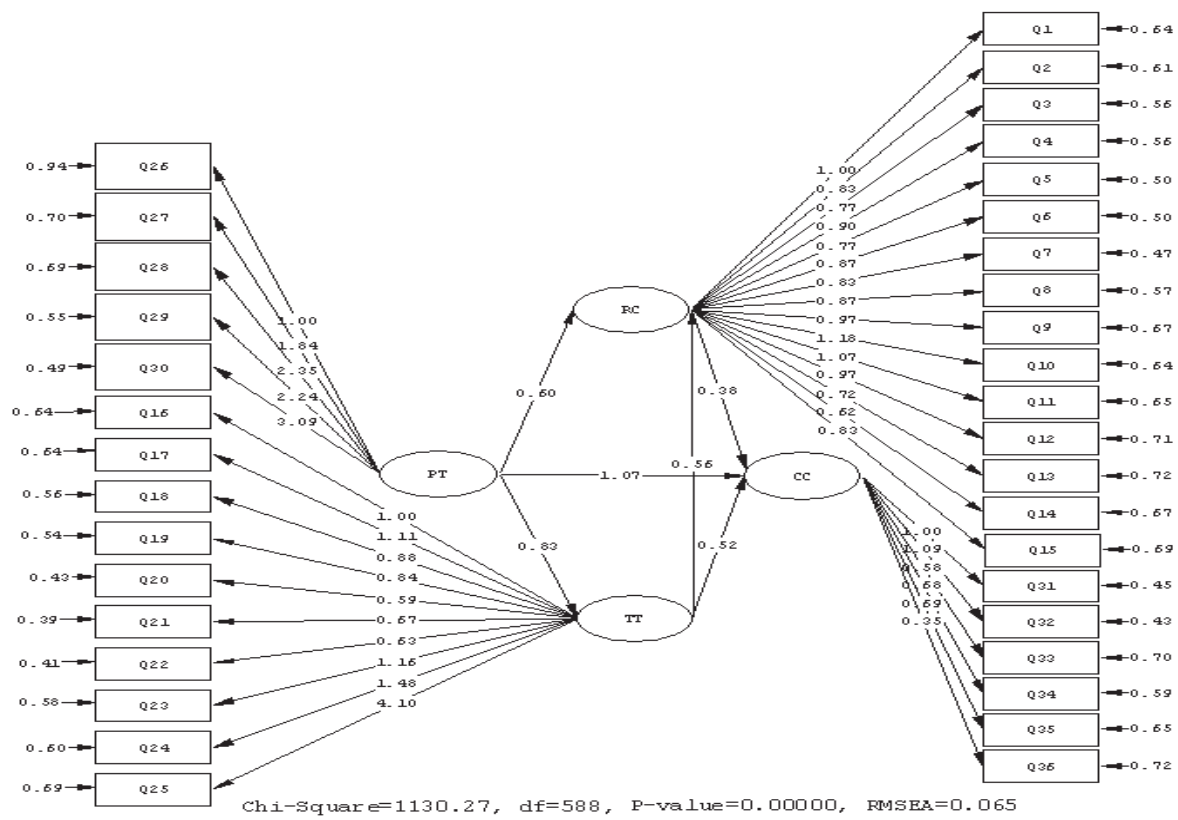

Figure 2. standardcoefficients of structural model and measurement model

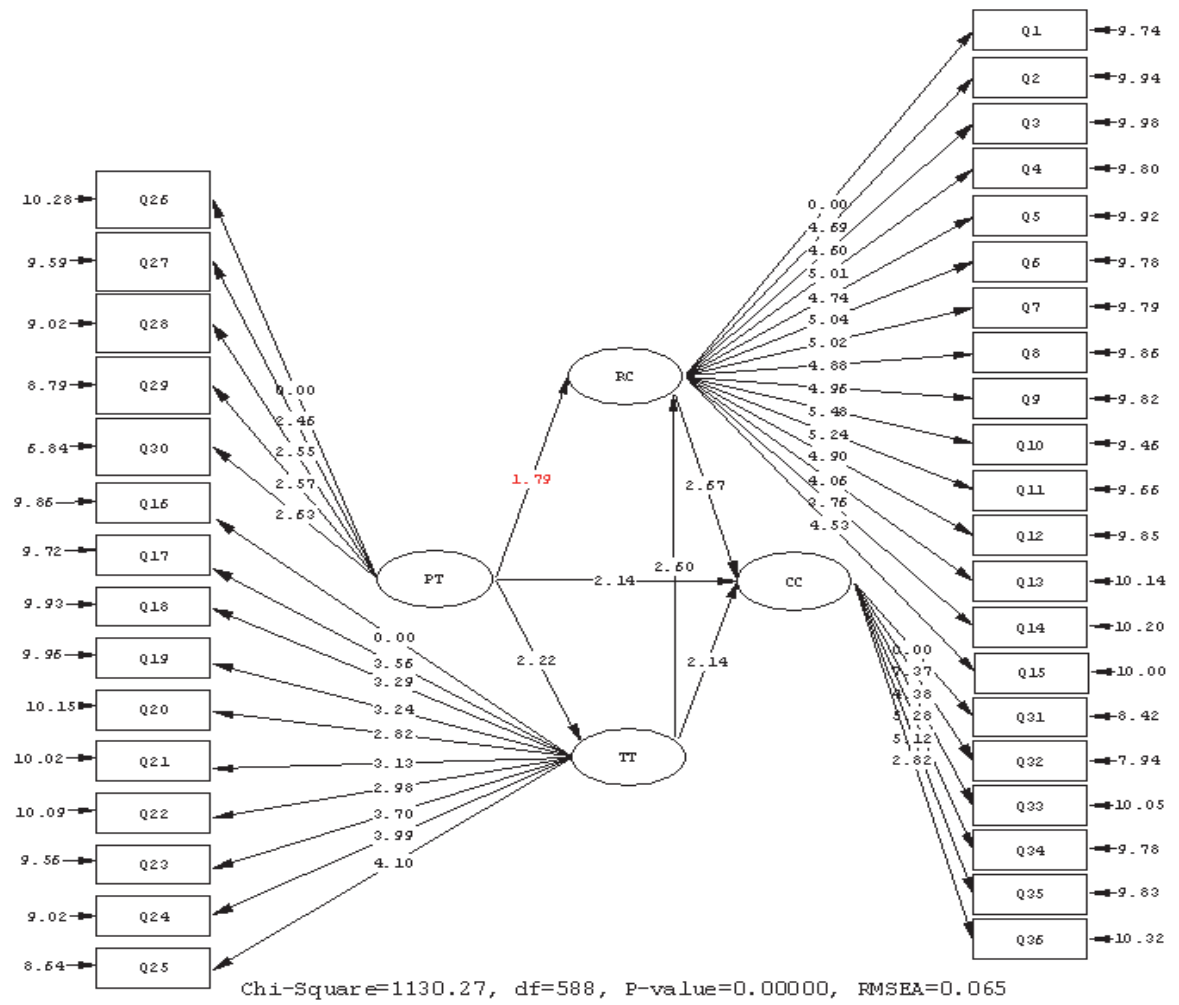

Figure 3. t statistic for coefficients of structural model and measurement model 


\section{Research Results}

As it can be seen in table 1, a $\lambda$ coefficient has been assumed as equal to 1.0 and measurement criterion for latent variable is determined based on it. Further, measurement scales of latent variables are held fixed.

Table 1. fit indices of the research model

\begin{tabular}{|c||c||c||}
\hline \multicolumn{1}{|c||}{ Macro } & Standard values & Estimated values \\
\hline \hline Degrees of Freedom & ------ & 588 \\
\hline \hline Chi-Square & It is not an appropriate criterion because of dependence on sample size & 1130.27 \\
\hline \hline RMSEA & 0.05 & 0.065 \\
\hline \hline $\mathrm{NFI}$ & 0.90 & 0.72 \\
\hline \hline $\mathrm{NNFI}$ & 0.90 & 0.84 \\
\hline $\mathrm{CFI}$ & 0.90 & 0.85 \\
\hline \hline $\mathrm{RMR}$ & 0.05 & 0.059 \\
\hline \hline $\mathrm{GFI}$ & 0.90 & 0.78 \\
\hline \hline $\mathrm{AGFI}$ & 0.90 & 0.75 \\
\hline
\end{tabular}

As it can be seen in table 1 , goodness of fit indices is all in acceptable level.

$Z$ statistic: this statistic is used when model fit is acceptable. If $Z$ value is greater than 1.96 , it is significant in $(0.05)$ significance level and when it is greater than 2.56 , it is significant in (0.01) significance level.

First hypothesis: personal trust has a positive influence on team trust.

Table 2: results of standard coefficients and t statistic

\begin{tabular}{|c||c|c|c||}
\hline \hline T statistic & Estimated coefficients & Dependent variable & Independent variable \\
\hline \hline 2.22 & 0.83 & Team trust & Personal trust \\
\hline
\end{tabular}

According to data summarized in table 2, the size of the impact of the independent variable on dependent variable is equal to 0.83 . this means that one single unitincrease in personal trust results in 0.83 unit increase in team trust. Because t statistic value is greater than 1.96, this relationship is supported by data (relationship is significant in $5 \%$ error level) $\left(t=2.22, \gamma_{11}=0.83\right)$.therefore, personal trust does influence on team trust.

Second hypothesis: team trust has a positive impact on commitment.

Table 3. results of standard coefficients and t statistic

\begin{tabular}{||c||c||c||c||}
\hline \hline T statistic & Estimated coefficients & Dependent variable & Independent variable \\
\hline 2.60 & 0.56 & commitment & Team trust \\
\hline
\end{tabular}

Results of table 3 show that data support the influence of the independent variable on the dependent variable and the path connecting these two variables is positive and significant (the relationship is significant in $5 \%$ error level) $\left({ }^{t=2.60, \beta_{11}=0.56}\right)$. Therefore, it can be said with $95 \%$ of certainty that team trust has a positive influence on commitment.

Third hypothesis: personal trust has a positive influence on participative performance.

Table 4. Results of standard coefficients and t statistic

\begin{tabular}{||c|c|c|c||}
\hline \hline T statistic & Estimated coefficients & Dependent variable & Independent variable \\
\hline \hline 2.14 & 1.07 & Participative performance & Personal trust \\
\hline
\end{tabular}

Results showed that in table 4, data support the influence of independent variable on the dependent variable and the path linking these two variables is positive and significant (in $5 \%$ error level) $\left(t=2.14, \gamma_{12}=1.07\right)$. Therefore, it can be said with 
95\% of certainty that personal trust influences participative performance.

Fourth hypothesis:: personal trust has a positive influence on commitment.

Table 5. Results of standard coefficients and t statistic

\begin{tabular}{|c|c|c||c|}
\hline \hline T statistic & Estimated coefficients & Dependent variable & Independent variable \\
\hline \hline 1.79 & 0.60 & commitment & Personal trust \\
\hline \hline
\end{tabular}

According to table 5 , data do not support the influence of independent variable on the dependent variable and the path linking these two variables is positive and insignificant (insignificant in 0.05 error level) $\left({ }^{t=1.79, \gamma_{13}}=0.60\right.$ ). Therefore, we cannot conclude that personal trust influences commitment positively with $95 \%$ of certainty.

Fifth hypothesis: team trust has a positive impact on participative performance.

Table 6. Results of standard coefficients and t statistic

\begin{tabular}{|c|c|c|c|}
\hline T statistic & Estimated coefficients & "Dependent variable & Independent variable \\
\hline 2.14 & 0.52 & Participative performance & Team trust \\
\hline
\end{tabular}

According to table 6 , data support the influence of independent variable on the dependent variable and the path linking these two variables is positive and significant (it is significant in $5 \%$ error level) $\left({ }^{t=2.14, \beta_{12}}=0.52\right)$. Therefore, it can be said with $95 \%$ of certainty that team trust has a positive impact on participative performance.

Sixth hypothesis: commitment has a positive influence on participative performance.

Table 7: results of standard coefficients and t statistic

\begin{tabular}{|c|c|c|c|}
\hline T statistic & Estimated coefficients & Dependent variable & Independent variable \\
\hline 2.67 & 0.38 & Participative performance & commitment \\
\hline
\end{tabular}

According to table 7, data support the influence of the independent variable on dependent variable and the path linking these two variables is positive and significant (it is significant in 0.05 error level) $\left(t=2.67, \beta_{21}=0.38\right)$. Therefore, it can be said with $95 \%$ of certainty that the independent variable has positive impact on participative performance.

\section{Conclusion}

Considering the results of the research in the first hypothesis analysis, we recommend training programs be held in Social Security Organization in order to increase personal trust among employees and working groups. Further, individuals who are honest and loyal must be employed as employees so that personal trust increases in employees.

Considering the results of the second hypothesis analysis, Social Security Organization can increase its communications outside its organizational structure chart by doing recreational tours and forming sports teams in order to increase sense of trust among employees. This will help employees increase friendship and commitment among employees.

Considering the results of the third hypothesis analysis, the author recommends that the organization should increase personal trust within the organization in order to increase employees' participative performance and avoid differentiation among employees so that sense of trust increases among employees. this results in participation increase. Management should guarantee the fact that employees' collaboration and participation is highly respected.

Considering the results of the fourth hypothesis analysis, since personal trust does not influence commitment, mutual interactions with employees can help increase commitment and thereby improve commitment. Factors like compatibility of employee and job, interaction between person and organization, satisfaction with working environment and colleagues improve commitment. Therefore, social security organization managers are proposed to establish a friendly atmosphere full of trust in the organization so that employees' commitment will increase. Therefore, spread of friendship and trust among managers and employees will develop this atmosphere and communications.

Considering the results of the fifth hypothesis, since team trust increases participation in employees' performance, 
improvement of sense of security and creation of mutual interactions improve team trust and therefore participative performance and involvement in organizational processes are also improved.

Considering the results of the sixth hypothesis analysis, managers can improve organizational trust and therefore improve relational commitment so that this finally results in increasing participation in performance. Managers can adopt different leadership styles. Implementation of appropriate leadership style can help management pay attention to employees. Management can prepare appropriate working conditions and safe atmosphere and inspire trust and friendly collaboration in order to increase employees' job satisfaction. Satisfied employees have positive attitudes towards their lives and are psychologically healthier. They are always present in organization and improve efficiency and this organizational happiness is conveyed to houses and society.

\section{References}

Allen , $N, J$.and Meyer , J.P.(1993). The Measurement and Antecedents of Affective, Continuance and Normative Commitment to the Organization. Journal of Occupational Psychology ,63.1-18.

Alvani, Danayeefard, public management and public trust, management knowledge, Tehran University press, 2001.

Branda, J.L. and Eccles, R.G. (2005), "Price, authority, and trust: from ideal types to plural forms", Annual Review of Sociology, Vol. 15, pp397-418.

Charlton, G. Human (2010), Habits of Highly Effective organizations, Van Schaik, Pretoria;25(2),pp.210-223.

Liu, L. and Luo, E. (2011), "Modeling trust for system design using the strategic actors framework", Lecture Notes in Computer Science, Vol.31,no,6,pp320-334.

Mogimi, S, M, 2006, "organization and management, a research approach", fifth printing, Termeh publications, Tehran.

Patnam, Rabert (2001), democracy and civil traditions, translated by: Mohammad Taghi Del Forouz, Tehran, political studies office, ministry of state. 